\title{
Multi-objective Demand Side Management at Distribution Network Level in Support of Transmission Network Operation \\ DOI:
}

10.1109/TPWRS.2019.2944747

\section{Document Version}

Accepted author manuscript

Link to publication record in Manchester Research Explorer

Citation for published version (APA):

Ponocko, J., \& Milanovic, J. V. (2019). Multi-objective Demand Side Management at Distribution Network Level in Support of Transmission Network Operation. IEEE Transactions on Power Systems, 35(3), 1822 - 1833.

https://doi.org/10.1109/TPWRS.2019.2944747

\section{Published in:}

IEEE Transactions on Power Systems

\section{Citing this paper}

Please note that where the full-text provided on Manchester Research Explorer is the Author Accepted Manuscript or Proof version this may differ from the final Published version. If citing, it is advised that you check and use the publisher's definitive version.

\section{General rights}

Copyright and moral rights for the publications made accessible in the Research Explorer are retained by the authors and/or other copyright owners and it is a condition of accessing publications that users recognise and abide by the legal requirements associated with these rights.

\section{Takedown policy}

If you believe that this document breaches copyright please refer to the University of Manchester's Takedown Procedures [http://man.ac.uk/04Y6Bo] or contact uml.scholarlycommunications@manchester.ac.uk providing relevant details, so we can investigate your claim.

\section{OPEN ACCESS}




\title{
Multi-objective Demand Side Management at Distribution Network Level in Support of Transmission Network Operation
}

\author{
Jelena Ponoćko, Member, IEEE, Jovica V. Milanović, Fellow, IEEE
}

\begin{abstract}
This paper proposes a methodology for advanced demand side management (DSM) in the distribution network (DN), catering at the same time for the requirements of the network operator, transmission or distribution, the available flexibility of the demand side, and the preservation of network performance. The basic premise of the study is that the distribution network operator is providing flexibility to the transmission system operator through load shaping. Different, one or more, indicators can be chosen to assess preservation of network performance. In this paper, for illustrative purposes of the methodology, the steady state voltage stability index, namely the load margin, is chosen as the network performance indicator. This is evaluated before and after a DSM action, in order to analyse the possible effect of DSM on network loadability. Load at each $\mathrm{DN}$ bus is represented using a realistic composite load model comprising controllable and uncontrollable loads. The DSM is initially performed based on optimal power flow calculation to ensure that the distribution system load profile at the grid supply point follows the required (pre-specified) load profile during a $\mathbf{2 4}$ hour period. Following this, a particle swarm optimisation is used to modify DSM program in those time steps of the planning horizon where load margin is reduced. The methodology is illustrated on a number of case studies using modified IEEE 33 bus distribution network model. The results illustrate the extent to which the available flexibility of demand can be used in support of transmission network operation when the preservation of network performance and appropriate load modelling are considered.
\end{abstract}

Index Terms-- Demand response, load modelling, distribution network, particle swarm optimisation, voltage stability

\section{NOMENCLATURE}

$\begin{array}{ll}B_{i k} & \begin{array}{l}\text { Imaginary part of the bus admittance matrix between } \\ \text { buses } i \text { and } k\end{array} \\ c_{1} & \begin{array}{l}\text { Acceleration constant of the tendency of the particle to } \\ \text { continue in the same direction }\end{array} \\ c_{2} & \begin{array}{l}\text { Acceleration constant of the tendency of the particle } \\ \text { towards the local best solution }\end{array} \\ c_{3} & \begin{array}{l}\text { Acceleration constant of the tendency of the particle } \\ \text { towards the global best solution }\end{array} \\ C F_{G} & \text { Cost function of generation } \\ C F_{D R} & \text { Cost function of load shift } \\ F_{\text {Fex }} & \text { Amount of total flexible load at bus } i \text { and time } t \\ G_{\text {best }}^{t} & \text { Global best solution of any particle at time step } t\end{array}$

This work was supported by the EU Horizon 2020 project "CROSSBOW", grant agreement $\mathrm{N}^{\circ} 773430$. The authors are with the Department of Electrical and Electronic Engineering, The University of Manchester, Manchester, UK. (e-mail: \{jelena.ponocko; milanovic\}@ manchester.ac.uk)

\begin{tabular}{|c|c|}
\hline$G_{i k}$ & $\begin{array}{l}\text { Real part of the bus admittance matrix between buses } i \\
\text { and } k\end{array}$ \\
\hline$N_{G}$ & Number of generator buses \\
\hline$N_{L}$ & Number of load buses \\
\hline$P_{\text {Con }, i, t}$ & $\begin{array}{l}\text { Amount of active load connected at bus } i \text { and time } t \\
\text { (payback load) }\end{array}$ \\
\hline$P_{D i s, i, t}$ & $\begin{array}{l}\text { Amount of active load disconnected (shifted) at bus } i \\
\text { and time } t\end{array}$ \\
\hline$P_{\text {For }, i, t}$ & Amount of active load at bus $i$ and time $t$ prior to DSM \\
\hline$P_{G, i}$ & Real power of generation at bus $i$ \\
\hline$P_{D, i}$ & Real power of demand at bus $i$ \\
\hline$P_{i_{\text {best }}^{t}}^{t}$ & Local best solution of the current particle at time step $t$ \\
\hline $\mathrm{P}_{\text {Dis. }}^{\mathrm{IM}}$ & $\begin{array}{l}\text { Amount of disconnected (shifted ) active induction } \\
\text { motor load }\end{array}$ \\
\hline$P_{C o n .}^{I M}$ & $\begin{array}{l}\text { Amount of connected (payback) active induction motor } \\
\text { load }\end{array}$ \\
\hline $\mathrm{P}^{\mathrm{Z}}{ }_{\text {Dis. }}$ & $\begin{array}{l}\text { Amount of disconnected (shifted) active constant } \\
\text { impedance load }\end{array}$ \\
\hline$P_{\text {Con. }}^{Z}$ & $\begin{array}{l}\text { Amount of connected (payback) active constant } \\
\text { impedance load }\end{array}$ \\
\hline$Q_{G, i}$ & Reactive power of generation at bus $i$ \\
\hline$Q_{D, i}$ & Reactive power of demand at bus $i$ \\
\hline$V_{i}$ & Voltage at bus $i$ \\
\hline$V_{i}^{M I N}$ & Lower voltage limit at bus $i$ \\
\hline$V_{i}^{M A X}$ & Upper voltage limit at bus $i$ \\
\hline$V S I_{\text {ref }}$ & Load margin before DSM \\
\hline$V S I$ & Load margin after load rescheduling \\
\hline$V_{i}^{t}$ & Velocity of a particle at time step $t$ \\
\hline$X_{i}^{t}$ & Position of a particle at time step $t$ \\
\hline$\Delta I M$ & Amount of flexible active induction motor load \\
\hline$\Delta Z$ & Amount of flexible active constant impedance load \\
\hline$\theta_{i k}$ & Voltage angle difference between buses $i$ and $k$ \\
\hline
\end{tabular}

\section{INTRODUCTION}

$\mathrm{T}$ HE evolution of the smart grid concept resulted in introduction of a variety of technologies and control options in the power network, especially at the distribution level. Distributed generation (including renewable), different new types of electric loads (electric vehicles, heat pumps), demand response/demand side management (DR/DSM), etc., will bring new challenges for the distribution network operator (DNO), primarily in the domain of network flexibility and stability, if it is to play a more prominent role in supporting transmission network operation in the future. One of the insufficiently explored flexibility providers so far is the DSM. (Note: DR and DSM will be used interchangeably in the rest of this paper, even though DSM is a more general term, while 
DR commonly refers to price-based programs.) Providing that there is appropriate regulatory framework, the DSM can be exploited to provide required flexibility instead of using costly fast ramping generation. The advantage of the aggregated DR is that variations of a large number of small devices are smaller than variations of a small number of large devices (conventional generators); therefore, decline of some small devices to participate in the network operation would have a smaller effect on the grid [1]. National Grid (the UK transmission system operator) has set a goal of securing 30$50 \%$ of balancing capability from demand side sources, mainly provided by the aggregators, by 2020 [2]. Many pilot sites around the world are investigating the potential of aggregated DR, including a pilot site with aggregated DR from 200 water heaters in the US [3], where the aggregator has to report the load forecast of its controllable load and the payback effect of the control action to the virtual power plant, with the intention to provide more than $11 \mathrm{MW}$ of ancillary services by controlling over 1200 loads.

Unlike conventional generators, DR (similar to energy storage) has limited duration of response, hence, load reductions have to be scheduled to provide energy services during periods of the highest value [4]. Furthermore, the aggregate response is more predictable and reliable than the one of individual end-users. Aggregation allows longer curtailments by sequential shedding of individual loads within the aggregated group, and varying response times from individual loads within the group [5]. Therefore, there is no need to model in detail operating characteristics of different types of load in the aggregation. Aggregated DR of individual consumers could even be transformed into a probabilistic demand curve, similar to generation availability curve of a renewable energy source (RES) [6]. Large-scale DSM can be used to provide balancing services to the DNO by selling flexibility [7], compensate RES volatility [8], provide regulation services [9], or defer investment and contribute to network security and reliability $[10,11]$. Typically reported applications of direct load control include voltage control, provision of ancillary services and energy arbitrage [12]. On the other hand, the yet unresolved requirements for the evolution of smart distribution grids are DR availability curves, as well as the stability analysis of distribution networks during DSM programs [13].

As the changes in distributed energy resources (DER), including flexible loads, at distribution level may influence the transmission network, the network performance indicators (such as frequency and voltage stability) should be recorded and maintained, if not improved during and after control actions. This paper focuses on illustrating the concept of advanced DSM by maintaining the chosen network performance indicator, before and after DSM action, in addition to providing desired demand profile over a set period of time. Voltage instability (also referred to as load instability) in the distribution system, which can spread to the transmission system and cause a major blackout [14], is chosen as a network performance indicator in this study. During a heavily loaded condition, even a relatively small but sudden increase in demand can result in voltage instability [15]. Load margin will be of a particular interest once the increase of large residential loads becomes significant as the penetration of electric vehicles (EVs), for example, could double the current DN load, at peak load hours in particular [16].

Wide-area DSM, including time shift of large portions of flexible loads across network buses (and consequently spaceshift of demand), will change not only the total demand in different regions of the network, i.e., power flow, but also demand composition (shares of static and dynamic load) at network buses. Demand size and composition have been repeatedly shown to have crucial impact on the nature of dynamic response of demand following a network disturbance, and consequently the impact on the overall network voltage and angular stability $[17,18]$. Therefore, the study presented in this paper considers two demand side-based limitations of DSM, namely distribution network load margin and the composition of aggregated distribution network demand (the demand "seen" from the transmission network).

Previous studies have dealt, to an extent, with the influence of DSM on voltage stability. In [19] DR was used in contingency events, to support voltage stability until reserve distributed generators (DGs) get connected. It was assumed that $100 \%$ of the demand was flexible, and that load could be completely curtailed at some buses, and increased (by the same amount) at others, to maintain the frequency. This approach, however, would be hardly feasible to deploy in reality, due to the limitations in load flexibility (both upwards and downwards). Authors in [20] used a multi-objective optimisation to allocate a limited number of network buses for provision of DR based on Pareto optimal solution. The objective function included: generation scheduling cost, voltage drop, voltage stability margin, network loss, and incentive payment while, crucially, the demand-side flexibility was assumed, but not clearly evaluated, and the effect of load payback was not accounted for. In both of these studies [19, 20] the load was modelled as a constant power, though the most unfavourable for voltage stability, as it usually does not reflect the behaviour of the actual load in the network. Authors in [21] considered DSM as an alternative to short-term voltage stability improvement. In this study the load was modelled as a composition of different static and dynamic loads, but the criteria for curtailment or shifting different load types was not defined. Similarly, [10] examined how DSM can affect the estimated voltage stability margin by considering different load models but fell short of performing optimal allocation of DSM for improving voltage stability.

This paper introduces a methodology for advanced DSM in a distribution network in support of transmission network operation. From a TSO's point of view, the ancillary services DSM is expected to provide are energy services (load shedding or shifting) and operating reserve (regulation, ramping or contingency reserve), the latter one requiring fast response (seconds to a few minutes) [22]. The aim of load scheduling presented in this paper is to flatten the daily loading curve of the distribution network by shifting controllable loads from peak to valley periods. Load flattening reduces the need for generator ramping and the number of system balancing actions [10], and at the same time facilitates keeping sufficient spinning reserve from the synchronous generators [23]. Load flattening was used as an illustration of 
the concept presented here though any other shape of the daily loading curve could be equally well used as a target for load scheduling (for example, reducing the system peak load).

The DSM program proposed in this paper builds on the methodology developed in [24], which facilitates the increased observability (decomposition into load categories) of the demand by monitoring consumption of electrical appliances at a limited number of end-users' premises enabled with the use of smart meters with sub-metering technologies and the application of artificial neural networks. This improved demand observability is used in this paper to allow: i) more accurate modelling of demand at each load bus; ii) better planning of the DSM program and its outcome by taking into account the forecasted composition and flexibility of the aggregated demand. The information about demand composition is used in this paper not only to plan a DR action and predict the behaviour of demand during the load payback at different load buses of the network, but also, for the first time, to assess the network performance indicators affected by the changes in load flows coming from the changes in the size and composition of demand. With such enabled better overall observability of demand and its flexibility, the key novelties introduced by the developed DSM approach described in this paper include:

i) the use of voltage stability index (load margin) as the illustrative network performance indicator, assessed before and after a DSM action, with the aim of verifying that it does not deteriorate after a DR action;

ii) preserving demand composition (load mix) at network buses after DSM as close as possible to the one before DSM to ensure minimal variation in load response to network disturbances.

The DSM program is thus tailored to meet the requirements of the transmission system operator (TSO), in this example load modulation, while ensuring voltage stability of the network (as the chosen network performance indicator) and maintaining demand composition. Furthermore, most DR programs currently in use are motivated by either economic benefit, maximising the use of renewables, or deployment of DR in contingency situations [19,25]. This paper introduced for the first time (as its third distinct novelty) consideration of the network performance as a constraint in daily planning of DR. And finally, in most cases in the past, the DSM programs relied on modelling demand using constant power load model, which completely neglects voltage sensitivity of demand [19, 20], or on using only one load type [26]. Unlike the previous work on DSM, the proposed methodology for the first time (as the fourth novelty of the approach) schedules, optimally and simultaneously, two controllable load types, namely constant impedance load and induction motors, so that, in addition to meeting target loading at GSP, the load margin (as a chosen illustrative network performance indicator in this study) after the DSM program is at least maintained, if not improved. The proposed methodology is illustrated on a number of case studies using the modified IEEE 33 bus test network.

\section{Methodology}

DSM in this paper is planned day ahead, with three objectives, met in three consecutive steps: 1) ensuring that the distribution network load follows a predefined load profile, taking into account load payback; 2) preservation of demand composition; 3 ) preservation/improvement of the load margin.

The first objective is met by applying optimal power flow (OPF) with participation of flexible load buses acting as distributed generators with negative output. The algorithm takes into account that different buses have different flexibility (controllability) during the day, and so the load shift at any bus and time step is limited by the available (predicted) load flexibility. The output of this optimisation step informs the operator how much of the flexible load should be shifted at each load bus and when, to ensure that the set load profile is followed as closely as possible.

The second objective is to keep the demand composition after DSM as close as possible to the one before DSM. Demand composition, given as the contribution of individual load components (e.g., induction motors, resistive loads, etc.), plays an important part in the dynamic response of demand following a disturbance in the network that could ultimately lead to voltage and/or angular instability [18]. Maintaining the same demand composition after a DSM action reduces the possibility of unexpected load behavior in case of a disturbance. The output of this optimisation step therefore informs the operator what portion of a particular type of flexible load should be shifted at each bus and when.

Finally, at the third step, the load margin at each time step (of the $24 \mathrm{~h}$ planning horizon) is checked and compared with the one before DSM. If at any time step of the planning horizon the load margin after DSM appears to be lower than a pre-specified tolerance range around the load margin before the DSM, the load dispatch (shift) is corrected at the corresponding time steps. In this paper, for illustration purposes, the pre-specified tolerance range is arbitrarily chosen to be 5\%, i.e., the new load margin should not be lower than $95 \%$ of the initial load margin. Other tolerance values can be used equally, depending on the criteria chosen by the network operator. Similar approach for the load margin tolerance level was reported in [26], where the critical network load was 5\% lower than the maximum network loading. The correction of the load margin is applied by optimising the load values of the controllable load components using particle swarm optimisation (PSO). Load components are further defined in the next section. The PSO method was chosen due to its proven applicability in economical dispatch [27] and OPF including voltage stability indicators [28], as well as higher computational speed over genetic algorithms [29], another heuristic optimisation method used in similar problems.

Fig. 1 illustrates the main steps of the proposed methodology. Once the loads are dispatched at every load bus of the network using OPF calculations (Level 1), voltage stability is assessed (Level 2), by running the active loadvoltage characteristic (PV curve) simulations. If the voltage stability index (VSI), i.e., the load margin, is lower than the threshold, the PSO is used to re-schedule the flexible loads, within their flexibility boundaries (lower and upper bound, $l b$ and $u b$, respectively), to allow for higher load margin (Level 3). The steps are further detailed in Section IV. The proposed algorithm is foreseen as a decision making tool used by the DNO, as part of the day-ahead planning of the DSM (load scheduling) program to meet the requirements at the grid 
supply point (GSP) specified by the TSO, while keeping the selected (one or more) network performance indicators within predefined limits.

Though not very common in the literature, the voltage stability of distribution network has been analysed in the past [14, 30-32]. It has been reported that the key factors affecting voltage stability of these networks are DER limits and sensitivity of the loads to voltage variation [33]. Therefore, DSM action resulting in changing composition of loads and such potentially the nature of their dependence on voltage could affect voltage stability of the network. The loading limit of the network as network performance indicator related to voltage stability is therefore suitable to illustrate the proposed methodology.

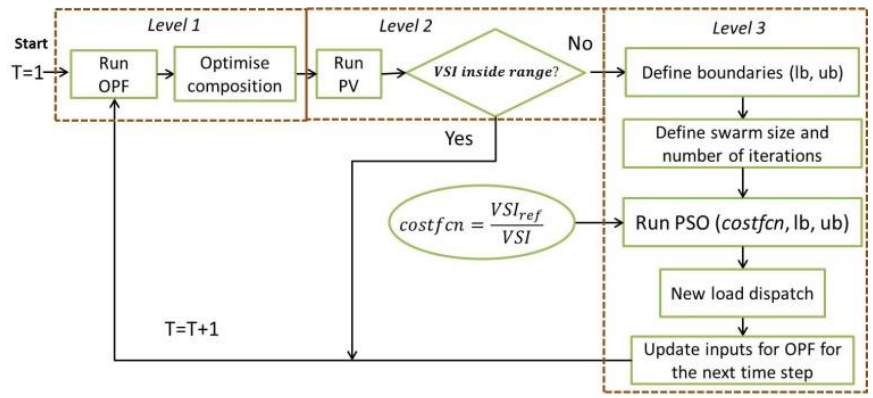

Figure 1 Flowchart of the proposed methodology

\section{LOAD MODELLING}

Unlike most papers dealing with DR and voltage stability simultaneously, this methodology uses a composite load model ([34]) instead of the constant power model to model system loads. This is done in order to account for different voltage dependency of different load types, both static and dynamic, and the effect it has on system steady state and dynamic performance. Load at every load bus is therefore modelled using the composite ZIP+IM load model, where the constant impedance (Z), constant current (I) and constant power $(\mathrm{P})$ load components are connected in parallel with the induction motor (IM) model [34]. Furthermore, Z loads are divided into controllable and uncontrollable, based on their suitability for DR, while all the IM loads are considered as controllable. The rest of the components are deemed uncontrollable. The composite load model at each load bus will thus consist of the 4 components (ZIP+IM), whose shares in the total load are different across different load buses, and also change during the day. Each load component comprises one or more load categories, which were originally defined in [18], and correspond to groups of typical home appliances: $i$ ) CTIM1 (constant torque induction motors - dish washers, washing/drying machines), ii) QTIM1 (quadratic torque induction motors - cold appliances), iii) $\mathrm{R}_{\mathrm{C}}$ (controllable resistive loads - water and space heating), iv) $\mathrm{R}_{\mathrm{UC}}$ (uncontrollable resistive loads - kitchen appliances), v) SMPS (switch mode power supply - electronic devices), and vi) Lighting. Mapping between the 4 load model components and 6 load categories is given in Table I. An example of a daily loading curve decomposed into load components and categories is given in Fig. 2.

The proposed demand composition may be simplistic if considered at lower demand aggregation level, as individual appliances have different behaviour depending on operating cycles (for example, a washing machine may be operating predominantly as a motor or as a heater, depending on the part of the operating cycle). These operating features of individual devices are of importance to the entity controlling and scheduling demand. From the network operator's point of view, however, it is not necessary to observe these differences among different appliances as the only effect that demand would have on system performance would be that of the aggregated demand at higher voltage levels. It has been demonstrated through measurements and long term monitoring that individual variability of devices is important at lower aggregation levels while it becomes much more "smooth" at the higher aggregation levels [35]. The proposed methodology focuses on aggregated demand at higher voltage levels, where the volatility of operating cycles of individual loads is less visible, if visible at all. At that aggregation level the modelling of demand using composite (ZIP+IM) load model is the most appropriate [36] as it takes care of both static and dynamic load components. The composite load model is therefore suitable to illustrate the extent to which demand flexibility can be harnessed if realistic load modelling is used to represent demand. The intrinsic demand limitations (with respect to flexibility and load payback, at aggregate level) are also considered to account for the fact that different appliances in customer premises cannot be disconnected for prolonged periods of time.

It should also be noted that the proposed load model does not include EVs and heat pumps, whose share in the distribution network load is currently low but will certainly grow in the future. These loads, once widely spread as they are expected to be in the future, can be easily incorporated in the methodology by changing the overall demand composition at different network buses. The main focus of this paper is to illustrate how and to what extent the currently prevailing aggregated demand (consisting of heating devices and induction motors, e.g., washing/drying machines, HVAC units, etc.) and its flexibility can be realistically harnessed through DSM at distribution network level to influence the network operation.

TABLE I

ZIP+IM LOAD COMPONENTS AND CORRESPONDING LOAD CATEGORIES

\begin{tabular}{l|l}
\hline ZIP+IM model component & Load category \\
\hline \hline$Z_{\mathrm{C}}$ (controllable constant impedance loads) & $\mathrm{R}_{\mathrm{C}}$ \\
\hline $\mathrm{Z}_{\mathrm{UC}}$ (uncontrollable constant impedance loads) & $\mathrm{R}_{\mathrm{UC}}$ \\
\hline $\mathrm{I}$ (uncontrollable constant current loads) & Lighting \\
\hline $\mathrm{P}$ (uncontrollable constant power loads) & SMPS \\
\hline $\mathrm{IM}$ (controllable induction motors) & CTIM1+QTIM1
\end{tabular}

The load payback, i.e., the reconnection of previously disconnected loads at the time steps following the disconnection, is accounted for in order to illustrate a realistic DSM program. One of the most common ways to model load payback is using linear increase of load [37], represented by the following equation:

$$
P B(t)=\alpha \cdot \Delta(t-1)+\beta \cdot \Delta(t-2)+\gamma \cdot \Delta(t-3)
$$

where $P B(t)$ is the payback load at time step t, $\Delta$ is the amount of shifted (disconnected) load (in MW), and $\alpha, \beta$ and $\gamma$ are the payback coefficients for load shifted from the three preceding time steps (three hours). This model is adopted for modelling the payback of the controllable $\mathrm{Z}$ loads in the paper. The approach assumes that all the loads disconnected at one time 
step get gradually re-connected in the following three time steps, i.e., $\alpha+\beta+\gamma=1$. It is also assumed that the approximately equal shares of the disconnected load are reconnected within the 3 hours after the DSM action, as suggested in [38]. Thus, 34\% of the disconnected $\mathrm{Z}$ loads will be reconnected in the first hour, the following $34 \%$ in the second hour and the last $32 \%$ in the third. In the case of IM loads, it is assumed that the users/aggregator are given the freedom to choose when to reconnect the loads, as long as it is during the valley periods (mostly night time). During the valley period, the load is lower than the one requested by the network operator. Therefore, all the disconnected IMs are reconnected randomly (following a uniform distribution), within the given periods of time and within 24 hours.

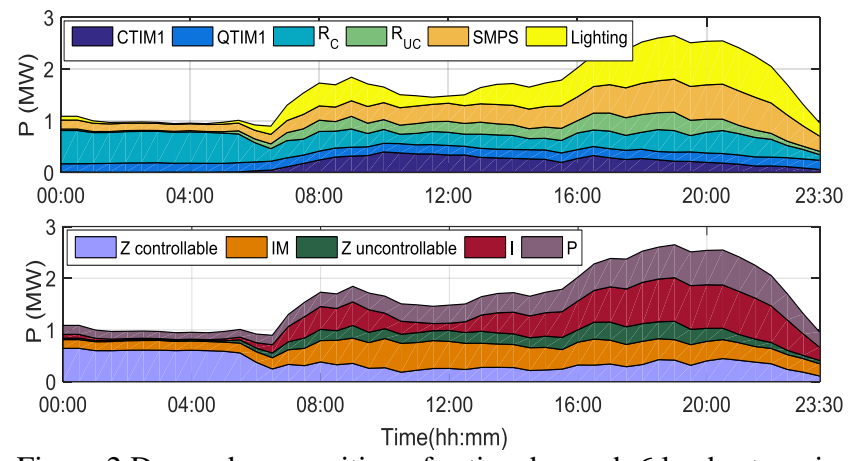

Figure 2 Demand composition of active demand: 6 load categories (top) and ZIP+IM composition (bottom)

A drawback of this generic, illustrative, load payback approach is that IM loads involve motors modelled as QTIM1 loads, i.e., cooling devices. These devices may not be deferrable for many hours. For example, it has been reported in [39] that food can only stay safe if the fridge has been turned off for up to 4 hours. Different load reconnection schemes and their effects should be considered in the future and demand reconnection should be modelled in more detail when considering actual implementation of DSM in real networks. In this particular case study, with the aim of illustrating the generic impact of load reconnection and significance of modelling of load reconnection (payback), QTIM1 loads do not represent a significant share in total load, which is why their load payback is not modelled separately.

These two payback models account for the end-users' commodity - they consider the usage of IMs as less comfortconstrained, i.e., the end-users are more tolerant to postponing the operation of the water appliances than the operation of the heating devices. Similar availability of these load types was reported in [10]. (Note: It is assumed that appropriate communication and control infrastructure exists in the distribution network, allowing for scheduling of the disconnection and reconnection of the load, as described in this section.)

\section{OPTIMISED DEMAND RESPONSE}

DR assets, similarly to most of the DER in the network, are energy constrained, which leads to a sequential decisionmaking problem [12]. Therefore, the load scheduling problem in this methodology is solved sequentially, in 48 consecutive steps of the planning horizon (with every step corresponding to 30 min period), taking into account load payback. The three objectives of the proposed DSM program, discussed in Section III, are met by using the following three optimisations:

Optimisation level 1: Shaping the load curve of the distribution network, i.e., flattening the load curve and minimising the load flow through the GSP in this illustrative example. The problem is solved as a typical OPF, given by expression (2), where the cost function $(C F)$ of generation and load shift is minimised. In this case, the highest generation cost is assigned to the GSP, while the flexible loads (acting as DGs with negative output) have the lowest cost in order to ensure that load follows generation.

$$
\min \left(\sum_{j=1}^{N_{G}} C F_{G}\left(P_{G, j}\right)+\sum_{k=1}^{N_{L}} C F_{D R}\left(P_{D i s, k}\right)\right)
$$

Subject to:

$$
\begin{gathered}
P_{G, i}-P_{D, i}=V_{i} \sum_{k=1}^{N} V_{k}\left[G_{i k} \cos \theta_{i k}+B_{i k} \sin \theta_{i k}\right] \\
Q_{G, i}-Q_{D, i}=V_{i} \sum_{k=1}^{N} V_{k}\left[G_{i k} \sin \theta_{i k}-B_{i k} \cos \theta_{i k}\right] \\
V_{i}^{M I N} \leq V_{i} \leq V_{i}^{M A X} \\
P_{D i, t}=P_{F o r, i, t}-P_{\text {Dis, }, i, t}+P_{\text {Con } i, t} \\
0 \leq P_{\text {Dis }, i, t} \leq \text { Flex }_{i, t}
\end{gathered}
$$

(2a) and (2b) are power flow equality constraints; (2c) refers to bus voltage limits; (2d) takes into account that the load value at each bus and each time step depends on the size of shifted (disconnected) load (calculated by OPF), and the size of payback (re-connected) load at that time step; (2e) are flexibility limits of the load, where Flex is the amount of flexible load.

Optimisation level 2: Keeping the demand composition, i.e., the shares of the four load components of the composite load model (ZIP+IM) at every bus, before and after the DSM action as close as possible. This will ensure that the demand at GSP will also have similar composition before and after DSM, at the given season and time of the day, hence similar dynamic response following network disturbance. In large-scale DSM scenarios, comprising many load buses in the network (distribution and/or transmission), the demand composition may be drastically changed at some times of the day, when large amounts of different load types are disconnected or reconnected. This may mean that load buses, which have predominantly static load during some time of the day, can end up having predominantly dynamic loads during those times due to the DSM actions. If a disturbance in the system happens at times when demand composition is different from the usual one, unforeseen dynamic response may happen and jeopardise the system stability. The proposed DSM program thus aims at preserving the same or similar demand composition compared to the one before DSM, to ensure a relatively unchanged dynamic response of demand in case of a disturbance, allowing the system operator to apply predefined (already known from practice) control actions to mitigate disturbed system operation. This is achieved by maximising the sum of shares of shifted (disconnected) IM loads $\left(\mathrm{P}^{\mathrm{IM}}{ }_{\text {Dis. }}\right)$ and $\mathrm{Z}$ loads $\left(\mathrm{P}^{\mathrm{Z}}{ }_{\text {Dis. }}\right)$, as shown by (3), while at the same time constraining these shares to ensure that demand composition is 
preserved. The constraints are given by (3a) which preserves the ratio of controllable loads, defined by $\Delta Z$ and $\Delta I M$, before (left hand side of the equation) and after DSM (right hand side), and by (3b) which keeps the disconnected loads within corresponding flexibility limits. $P^{I M}{ }_{\text {Con. }}$ and $P^{Z}$ con. in (3a) are payback (reconnected) IM and Z load, respectively. (3c) limits the sum of the disconnected shares by the total disconnected load calculated at the first optimisation level. (Note: Alternatively, one could preserve the share of total $\mathrm{Z}$ and IM loads in equation (3a) instead of controllable $\mathrm{Z}$ loads and IM loads, or the overall static demand, i.e., ZIP loads and IM loads. The resulting demand composition would be very similar and the effect on load margin hardly distinguishable irrespectively of the approach used. This is because the DR program relies on controlling more than one load type simultaneously (two different load types composed of a number of small users in this case), as it would be most likely the case in domestic load environment. The final load composition is further affected by considering the payback load. In wider scale DR programs, however, deployed in large distribution networks and relying on one type of load only, e.g., HVAC, or in the case of DR programs involving large industrial users (likely to have significant component of IM loads or one type of load only), the change in load composition following deployment of DR program would be more significant and consequently its effect on network performance indicator (load margin in this case) more pronounced.)

Subject to:

$$
\max \left(\mathrm{P}^{\mathrm{Z}}{ }_{\text {Dis. }}+\mathrm{P}^{\mathrm{IM}}{ }_{\text {Dis. }}\right)
$$

$$
\begin{gathered}
\frac{\Delta I M}{\Delta Z}=\frac{\Delta I M-P^{I M}{ }_{\text {Dis. }}+P^{I M}{ }_{\text {Con. }}}{\Delta Z-P^{Z}{ }_{\text {Dis. }}+P^{Z}{ }_{\text {Con. }}} \\
0 \leq P_{\text {Dis. }}^{Z} \leq \Delta Z ; \quad 0 \leq P^{I M}{ }_{\text {Dis. }} \leq \Delta I M \\
\mathrm{P}_{\text {Dis. }}+\mathrm{P}^{I M_{D i s .}} \leq P_{\text {Dis. }}
\end{gathered}
$$

Optimisation level 3: Maintaining or improving load margin of the distribution network. The PSO algorithm is used to reschedule the controllable load shift every time the load margin after DSM is estimated to be lower than $95 \%$ of the load margin before DSM. The load margin reflects the distance of the current operating point of the system to the maximum loading point, and is commonly determined from the active load-voltage characteristic (the PV curve), as shown in Fig. 3 (adapted from [40]).

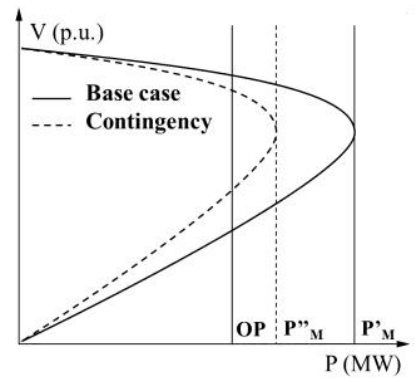

Figure 3 PV curve (adapted from [40])

If the current operating point (OP) is at the upper half of the PV curve, the real power margin is the amount of load increase that will cause the power system to reach the maximum loading point ( $P_{M}^{\prime}$ in Fig. 3). The change in network parameters (due to a contingency, for example) changes the PV characteristic (dashed curve in the figure), while the change in load (constant power load characteristic is used in Fig. 3 to illustrate the concept) changes the position of the OP on the PV curve, and consequently the load margin. Changing the network parameters, by adding FACTS devices, for example [41], moves the PV characteristic, while changing the load by DSM action can move the OP to the left or to the right (along the PV characteristic), and such increase or decrease its distance to the maximum loading point, respectively. Keeping the load margin as large as possible ensures that the system will be able to withstand disturbances and unexpected increase in the load without endangering its voltage stability. In order to ensure that the load margin is maintained, the PSO algorithm is minimising the objective function (4) subject to (3b), where $V S I_{\text {ref }}$ is the load margin prior to the DSM action, and VSI is the load margin after rescheduling the demand shift.

$$
\min \left(\frac{V S I_{r e f}}{V S I}\right)
$$

PSO belongs to the group of heuristic optimisation methods, along with genetic algorithms and evolutionary algorithms [42]. These methods start from a random choice in the search space and, based on the evaluation of the objective function in every iteration, gradually move the position of the result vector to the optimal one. In the PSO method, a swarm (population) of candidate solutions (particles) is generated in the first iteration, and the positions of particles are updated in the following iterations based on the values of the objective function. The basic PSO algorithm consists of three steps: generating particles' positions and velocities, velocity update, and position update [29]. The initial positions and velocities are allocated randomly, from the search space, and the velocities are updated in the following iteration based on the values of the fitness function of the particles within a swarm. The velocity update uses information about the particle with the best global value in the current swarm $\left(P_{i_{\text {best }}}^{t}\right)$, and the best position of each particle over time $\left(G_{\text {best }}^{t}\right)$. Finally, the particle position is updated based on the velocity update $\left(V_{i}^{t+1}\right)$. The position of the i-th component of the particle vector $X\left(X_{i}^{t+1}\right)$ is updated based on the previous time step $t$, and following (5) and (6):

$$
\begin{gathered}
X_{i}^{t+1}=X_{i}^{t}+V_{i}^{t+1} \\
V_{i}^{t+1}=c_{1} V_{i}^{t}+c_{2} \operatorname{rand}(0,1)\left(P_{i_{\text {best }}^{t}}^{t}-X_{i}^{t}\right) \\
+c_{3} \operatorname{rand}(0,1)\left(G_{\text {best }}^{t}-X_{i}^{t}\right)
\end{gathered}
$$

where $c_{1}, c_{2}$ and $c_{3}$ are acceleration constants, defining the linear attraction towards the direction of the particle. Coefficient $c_{1}$ defines the tendency of the particle to continue in the same direction, while $c_{2}$ and $c_{3}$ define attraction towards the local best (ever found by the given particle) and global best solution (ever found by any particle), respectively [43]. The first coefficient should not be too large or too small, to prevent slow or premature convergence, respectively. The experiments showed that the optimal value for $c_{1}$ is 0.7 or 0.8 , while the value for $c_{2}$ and $c_{3}$ is between 1.5 to 1.7 [44].

The PSO algorithm is applied in Matlab, with the swarm size (number of particles) set to 100. Matlab default values for acceleration constants of $0.1 \leq c_{1} \leq 1.1$, and $c_{2}=c_{3}=1.5$ are used. The required number of iterations was determined by observing the convergence process. The simulations were 
initially run with a large number of iterations and the cost function value was recorded at every iteration. Once this value stabilised over a number of iterations, the required number of iterations was fixed. The cost function of the applied PSO algorithm converged to a fixed value after 13 iterations in a large majority of the cases. This number was therefore, chosen as the maximum number of iterations, i.e., the cut-off point, in order to reduce the computational time. The iterative process stops when either, the maximum number of iterations (13 in this case) is reached, or when the cost function reaches a limit value equal to 1 (i.e., the new load margin is equal to the one before DSM). Therefore, the aim of the optimisation is not necessarily to maximise the load margin, but to keep it unchanged after the DSM action. The man reason for this is reduction of computational time. It should be noted that the minimum cost function of the PSO algorithm is not obtained when all resources of one or both controllable load types are disconnected, but rather a certain combination of the two, determined by the algorithm.

The overall algorithm takes up to 22 minutes to run (for 24 hour planning horizon, i.e., 48 time steps, including the PSO simulations with 13 iterations) on a PC with the 64-bit operating system and $3.40 \mathrm{GHz}$ processor. There is certainly a scope for reducing the computational time, however, this is not affecting the implementation and the illustration of the proposed methodology, hence it was not considered as a priority in this study.

(Note: A multi-period OPF with energy constraints on DR assets could be potentially used to solve the above problem, however, once demand composition and load margin (and possible other indices, e.g., those related to angular and frequency stability) are incorporated as constraints in the optimisation problem, the problem becomes much more complex to solve due to dimensionality. Considering the present limitations of the simulation environment, it was deemed sufficient to use the approach described in the paper relying on available and widely recognised software tools to illustrate a concept of advanced DSM, rather than developing custom made software from scratch for this purpose.)

\section{TEST NETWORK}

The test network used in this study is a slightly modified IEEE 33-bus network shown in Fig. 4. The network has one GSP, modelled as a slack bus, and one DG. It represents a distribution network providing ancillary services to the transmission network by reducing the need for balancing operations (by keeping the load at GSP as flat as possible, or as requested by the TSO). Alternatively, it is almost a selfsufficient distribution network (relying on power generated by its distributed generation, and adjusting its flexible load to it).

The first two optimisation steps (OPF and maintenance of demand composition) are run in Matpower; PV curve simulations are run in DIgSILENT/PowerFactory, while the PSO algorithm is run in Matlab. The DG has a constant output, and the loads are dispatched in order to follow the available generation and minimise the flow through the slack bus. The two aforementioned network operating scenarios can be presented using this DG:

i) if the network operates as a distribution network providing ancillary services to the TSO, the DG simulates the arbitrary load profile set/requested by the TSO (Note: In reality, the load resulting from the DSM action would be supplied through the slack bus, i.e., the GSP, not the DG, which only serves here to model the desired loading curve.);

ii) if the distribution network operates as a self-sufficient network, it minimises its dependency on the rest of the upstream network by controlling flexible loads to follow the available generation from the DG. In both scenarios, only load flexibility is harnessed, and no changes in DG output are made.

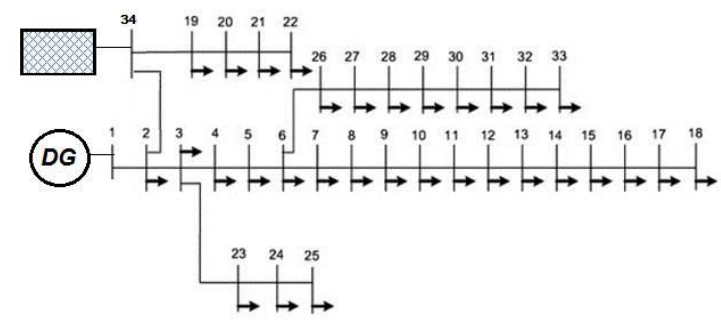

Figure 4 Modified IEEE 33-bus network

The generation cost of the DG only formally participates in cost minimisation, as the output of the DG is fixed and serves only to model the target loading curve that aggregated flexible loads should adjust to. The cost function $(C F)$ of the DG is linear $\left(C F_{G, 1}=10 \cdot P_{G, 1}\right)$, while the cost function of the slack bus (acting also as a generator) is quadratic $\left(C F_{G, 34}=1000\right.$. $P_{G, 34}{ }^{2}$ ), to minimise the flow (either positive or negative) through the slack bus. The cost function of load shifting is linear $\left(C F_{D R, 2-33}=10 \cdot P_{D i s, 2-33}\right)$.

All the load buses ( 32 of them) are considered to be controllable, however each load bus has different load composition and hence different controllability during the day. Each flexible load bus in the network model represents a secondary substation supplying around 50 residential endusers. The default load values for the network buses (real and reactive power in the IEEE model) are taken as the maximum daily values. The assigned daily load curves and demand composition are generated using the CREST load model, as detailed in [24]. For simplification, power factor (PF) is taken to be the same for all IMs and equal to 0.8 (which was the average value of the $\mathrm{PF}$ for the observed dataset given in [24]). Since the uncontrollable loads do not get shifted, the only PF change in the total load will come from shifting IMs and controllable $\mathrm{Z}$ loads (which are considered to have unity PF). As the typical consumption of residential IMs ranges between several hundreds and several thousands of Watts [45], it is adopted, for simplicity reasons, that each IM connected to the load bus in DIgSILENT/PowerFactory has the load of $1 \mathrm{~kW}$. This is required as the change in consumption of the IMs in DIgSILENT/PowerFactory is modelled by changing the number of motors (each having a constant load of $1 \mathrm{~kW}$ ) connected in parallel at a load bus. Higher granularity than this one was deemed unnecessary. Load payback of IM loads is thus modelled in the following way: if at a time step $t, 10 \mathrm{~kW}$ of IM loads is disconnected at one bus, these 10 units of $1 \mathrm{~kW}$ will be randomly (following uniform distribution) reconnected (at the same bus) during the valley periods (only valley periods following load disconnection are taken into account, i.e., only load deferral is possible). 


\section{CASE STUDIES}

The proposed DSM methodology is demonstrated on a set of seven case studies, listed in Table II. In each case the effectiveness of load shaping is evaluated with peak to average ratio (PAR) [10]; the closer this ratio is to 1 , the more successful load shaping is. In addition, distribution network losses were observed before and after the DSM action, to evaluate the extent to which load shaping contributes to their reduction, as they represent a significant share in the overall operational costs of a DNO, affecting the carbon emissions and generator capacity requirements [46]. For example, the losses reported in the UK distribution network, are $1.5 \%$ at $33 \mathrm{kV}$ level, and $3 \%$ at $11 \mathrm{kV}$ level [46].

In the case study $\mathrm{A}$, a subcase with preserved composition (case A.1) was compared with the cases when composition is not preserved, but either IM (case A.2) or Z (case A.3) loads are prioritised (disconnected first) to meet the desired load shift. If all the resources of one flexible load type are used up, and they still do not meet the demand reduction requirement, the appropriate amount of the other load type is then disconnected.

\begin{tabular}{c|c}
\multicolumn{2}{c}{ TABLE II } \\
CASE STUDIES \\
\hline Case study & \multicolumn{1}{c}{ Subcases } \\
\hline \multirow{2}{*}{ A. Base case (3 MW peak load) } & A.1 Preserved composition \\
\cline { 2 - 2 } & A.2 Prioritisation of IM loads \\
\cline { 2 - 2 } & A.3 Prioritisation of Z loads \\
\hline B. Case with limited acceptability & B.1 Preserved composition \\
\hline C. Overloaded system & C.1 Preserved composition \\
\hline D. Critically loaded system & D.1 Preserved composition \\
\hline E. Neglected DSM constraints & E.1 Constant power model \\
\hline
\end{tabular}

Case B observes a scenario where different load buses show different shares of customers which accept to participate in the DR program. Therefore, it is assumed that different buses have, randomly, $20 \%, 50 \%$ or $80 \%$ acceptability level, which reduces the DSM potential. Case studies C and D illustrate operating scenarios of overloaded and critically loaded systems. The base case load (case study A.1) is scaled by factor 2 and 4 in case studies $\mathrm{C}$ and D, respectively [47]. Finally, case study E illustrates how different the DSM outcome is when the load is modelled as constant power, and constraints such as load payback and load margin are neglected.

A.1 Base case with preserved composition: Fig. 5 illustrates the network loading curve over the 24 hour planning horizon (48 time steps) before and after the DSM. It can be seen that the resulting loading curve (solid black line) is in some time steps changed due to the activation of the PSO algorithm, triggered when there was a need to improve the load margin (Fig. 6). As seen in Fig. 6, the PSO algorithm successfully improves the load margin in the corresponding time steps, marked with circles, keeping it above the $95 \%$ limit, as mentioned in Sections II and IV.

Comparison of Case A.1 with A.2 and A.3: Fig. 7 demonstrates how different approaches (A.2 and A.3) in the choice of disconnected load components can change the resulting loading curve. In these two subcases the peak reduction is higher compared to case A.1 (which can also be seen from the PARs reported in Table III), however DSM action deteriorates the load margin in more time steps, which requires corrective actions (PSO algorithm), as shown in
Fig. 8, where some of these steps are marked with circles. Before DSM, maximum daily losses were $0.11 \mathrm{MW}$, while in the case of preserved composition they were $0.094 \mathrm{MW}$ (reduced by 14\%), and in the case of prioritised IM or Z loads the maximum losses were $0.074 \mathrm{MW}$ (reduced by $33 \%$ ). Average daily losses and the percentage losses for the three compared subcases are given in Table III. Fig. 9 illustrates the shares of controllable loads within the total daily load (in p.u.) before and after DSM for cases A.1-A.3. Due to the limited flexibility of $\mathrm{Z}$ and IM loads, load payback and load changes after PSO, the initial composition is not maintained in all the time steps of case A.1. Cases A.2 and A.3 result in different shares of IM loads during the day, while the shares of $Z$ loads are very similar to case A.1 - mainly due to the similar amount of total shifted $\mathrm{Z}$ loads and the corresponding $\mathrm{Z}$ load payback in all three cases.

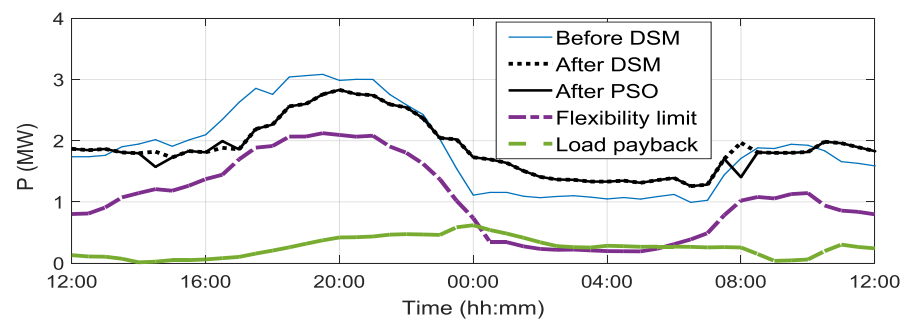

Figure 5 Network loading for case A.1

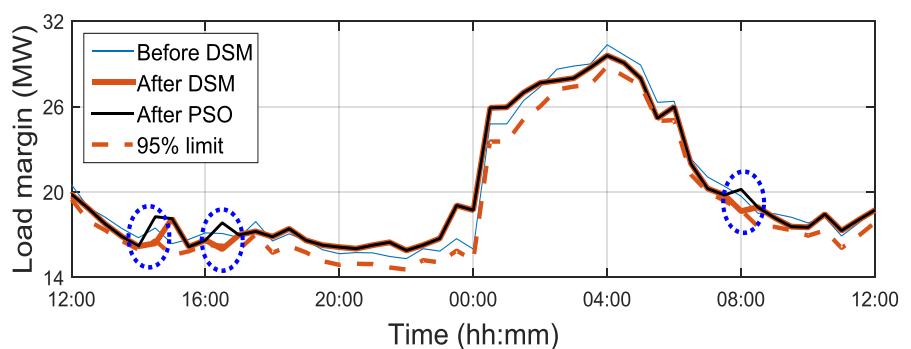

Figure 6 Load margin for case A.1

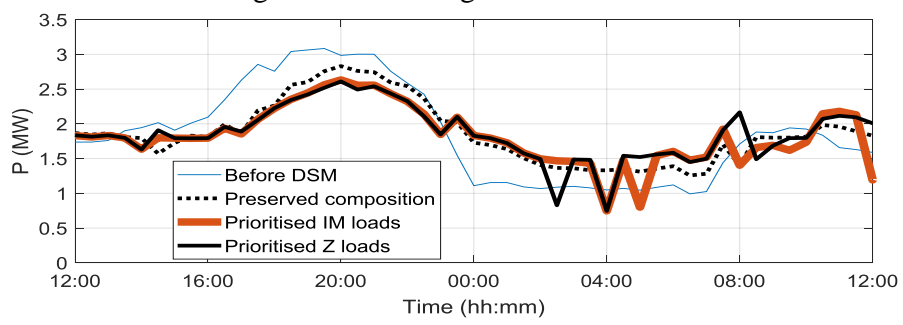

Figure 7 Network loading for cases A.1-A.3

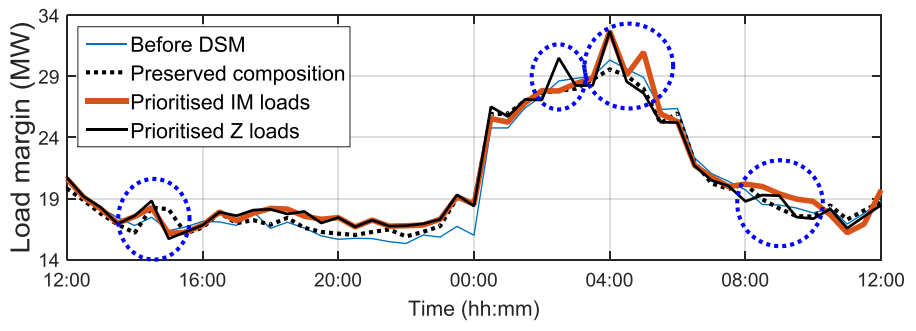

Figure 8 Load margin for cases A.1-A.3

B.1 Case with limited acceptability: Due to the limited acceptability of DSM by the end users, and consequently reduced load controllability, the loading curve after DSM could not be as flattened as in the previous three cases (Fig. 10). Since the load was less modified, the load margin was not deteriorated at any time step (Fig. 11). The effect of DSM on the PAR and network losses is shown in Table III. 


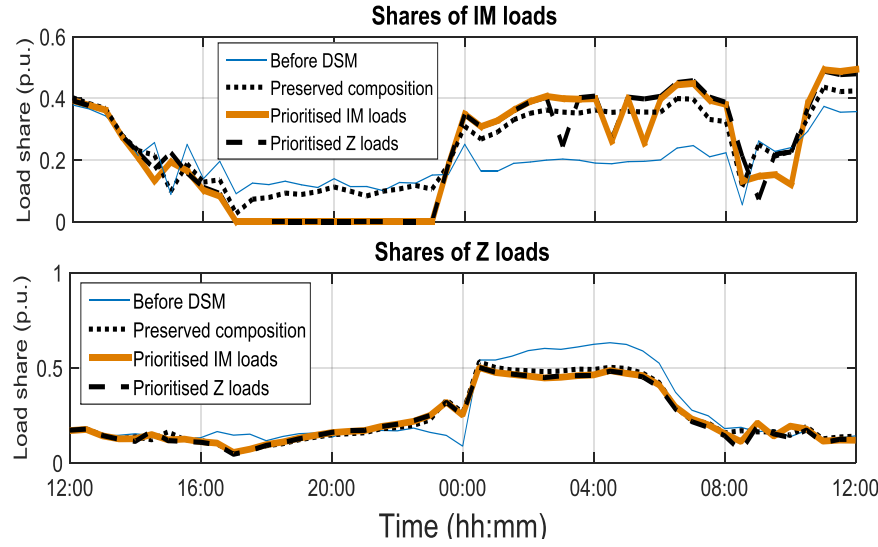

Figure 9 Shares of controllable demand for cases A.1-A.3

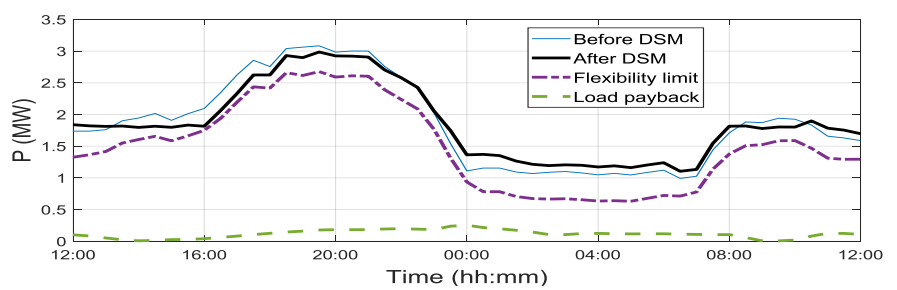

Figure 10 Network loading for case B.1

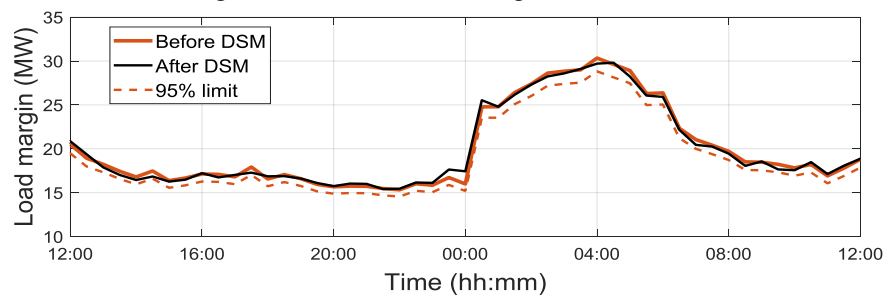

Figure 11 Load margin for case B.1

C.1 and D.1 Overloaded system and critically loaded system: The DSM effectiveness in these two cases is shown in Table III. It can be seen that the load shaping was not as successfully performed as before, due to the increased load payback, especially after the PSO algorithm, when larger amounts of load were reduced to preserve the load margin. Fig. 12 illustrates the change in load margin before and after DSM for cases A.1, C.1 and D.1, where the positive values imply improvement and negative ones deterioration of the load margin. The load margin improvement (increase) is seen in most time steps, especially for overloaded and critically loaded system. Although the network losses in cases C.1 and D.1 were still high after the DSM (as seen in Table III), the DSM program reduced the losses significantly. Apart from the values given in Table III, cumulative daily losses (given as energy in MWh) were analysed: these losses were reduced from $4.56 \mathrm{MWh}$ to $3.9 \mathrm{MWh}(14 \%$ reduction $)$ in the overloaded system. In the case of the critically loaded system, the reduction of cumulative daily losses after DSM was even more pronounced - from 19.34 MWh to 15.35 MWh (21\% reduction).

E.1 Neglected DSM constraints: Case E.1 confirms that the success of the DSM program (in this case load shaping) can be substantially overestimated when the aforementioned constraints (load payback and loadability) and the appropriate modelling of load are not taken into account, as demonstrated by smaller value of PAR in Table III. The network losses can also be overestimated due to the use of constant power load model. Fig. 13 represents the resulting load curve. Since there is no load payback, the loading curve is not increased during valley periods. During peak (afternoon) hours all the load flexibility is harnessed, as seen in overlapped loading curve (thick black line) after DSM and flexibility limit curve (dashed violet line). Even though the peak load is successfully reduced, the load margin after DSM is deteriorated in some time steps (marked with circles), as illustrated in Fig. 14. It should be noted that in larger networks the effect of neglecting intrinsic limitations of demand shift could be more significant.

Finally, Fig. 15 compares the resulting loading curve in cases A.1 and E.1, showing more successful curve flattening in case E.1. Fig. 16 shows how "optimistic" the load reduction is when the aforementioned constraints are neglected compared to the base case (A.1), which is accounting for these constraints (namely composite load model, load payback and load margin). In both cases the changes are calculated using the same base load before DSM.

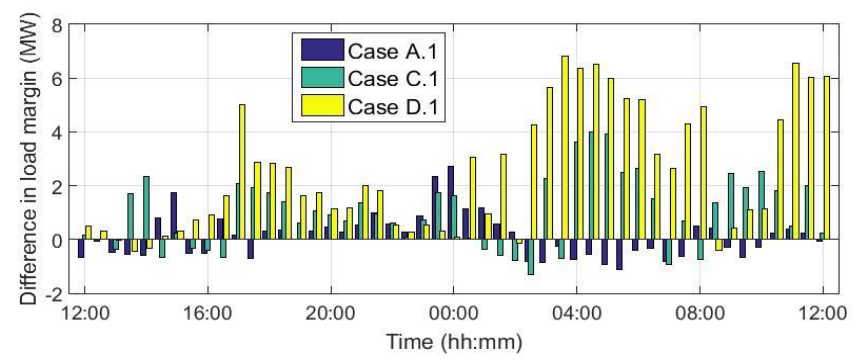

Figure 12 Difference in load margin (after DSM+PSO)

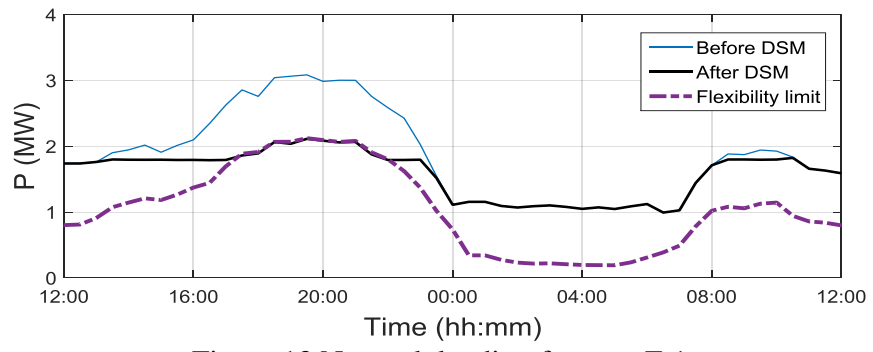

Figure 13 Network loading for case E.1

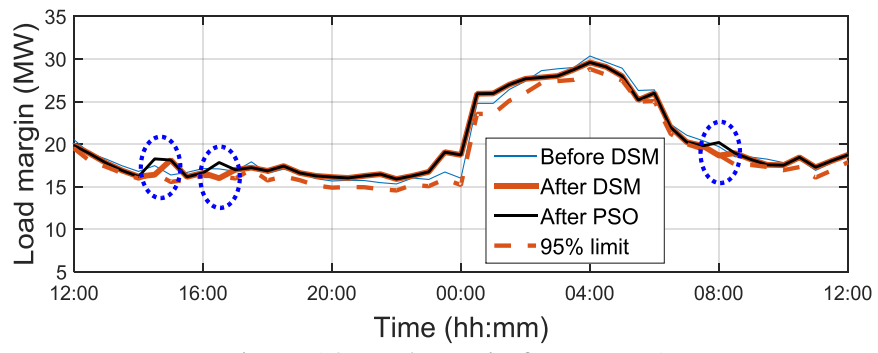

Figure 14 Load margin for case E.1

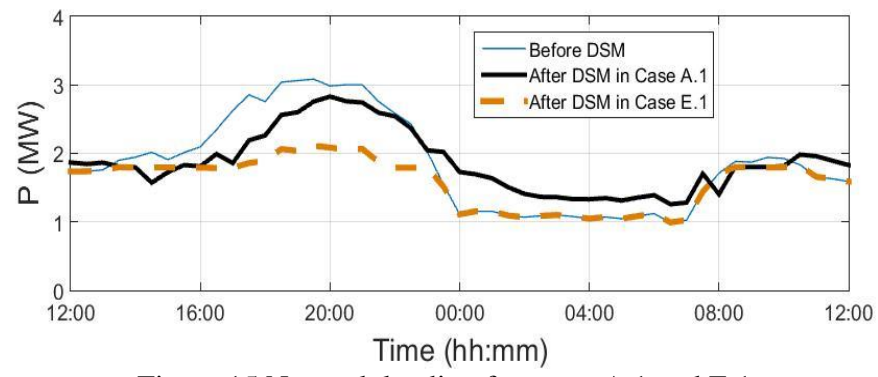

Figure 15 Network loading for cases A.1 and E.1 


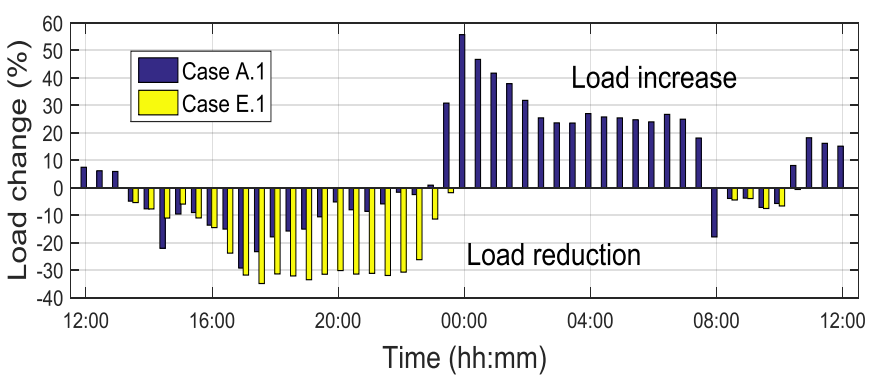

Figure 16 Load change after DSM for cases A.1 and E.1

During the peak load period (between $2 \mathrm{pm}$ and midnight), the load reduction in most steps of case A.1 ranges between $5 \%$ and $15 \%$, while in case E. 1 the reduction is almost constantly above $30 \%$. This shows that the expectations in load reduction may be two times higher when the realistic constraints are not taken into account. Similarly, during the valley period (between midnight and $8 \mathrm{am}$ ), where case E.1 neglects the load payback (thus there is no change in demand), the load increase in case A.1 due to load payback reaches almost $60 \%$. Even though this happens during the valley period in the given example, the demand increase is significant and shows the importance of load payback modelling in DSM studies.

\begin{tabular}{c|c|c|c}
\multicolumn{3}{c}{ TABLE III } \\
\cline { 1 - 1 } Subcase & $\begin{array}{c}\text { Peak to } \\
\text { average ratio } \\
\text { (PAR) } \\
\text { before/after } \\
\text { DSM }\end{array}$ & $\begin{array}{c}\text { Average daily losses/ } \\
\text { daily percentage } \\
\text { losses before DSM }\end{array}$ & $\begin{array}{c}\text { Average daily losses/ } \\
\text { daily percentage } \\
\text { losses after DSM }\end{array}$ \\
\hline \hline A.1 & $1.66 / 1.51$ & & $0.043 \mathrm{MW} / 2.3 \%$ \\
\hline A.2 & $1.66 / 1.44$ & \multirow{2}{*}{$0.046 \mathrm{MW} / 2.4 \%$} & $0.039 \mathrm{MW} / 2.2 \%$ \\
\hline A.3 & $1.66 / 1.40$ & & $0.040 \mathrm{MW} / 2.2 \%$ \\
\hline B.1 & $1.66 / 1.60$ & & $0.046 \mathrm{MW} / 2.4 \%$ \\
\hline C.1 & $1.66 / 1.59$ & $0.186 \mathrm{MW} / 5.0 \%$ & $0.159 \mathrm{MW} / 4.5 \%$ \\
\hline D.1 & $1.66 / 1.65$ & $0.790 \mathrm{MW} / 10.4 \%$ & $0.626 \mathrm{MW} / 9.4 \%$ \\
\hline E.1 & $1.66 / 1.33$ & $0.053 \mathrm{MW} / 2.8 \%$ & $0.041 \mathrm{MW} / 2.5 \%$ \\
\hline
\end{tabular}

\section{CONCLUSION}

This paper presented a comprehensive methodology for optimal scheduling of distribution network loads in support of transmission network operation. The main objective of the proposed DSM program is the load profile shaping, as a balancing service to be offered to TSO while maintaining the load composition and one or more network performance indicators (the distribution network loadability in this case) to values they had prior to the DSM action. The influence of load modelling, limited demand flexibility (including customers' willingness to participate in the DSM program) and load payback was taken into account, illustrating the importance of considering realistic assumptions when estimating the success of a DSM program. In order to preserve the loadability of the network (as in the case study illustrated in this paper, or more generally, any other network performance indicator) after the DSM action, a trade-off between the opposing objectives must be struck and the load profile of the distribution network has to be "tailored" considering both the requirements of the network operator, and preservation of the chosen network performance indicators.
Results of the presented case studies have shown that meeting the predefined target load curve can be limited by the aforementioned constraints, including intrinsic nature of demand and its flexibility on one hand, and the preservation of network performance on the other. Furthermore, instead of considering that the aggregated demand can be represented by constant power load, as in most cases in the past work on DSM, the proposed DSM methodology models the load using the most comprehensive, composite load model and schedules in an optimal way two controllable load types, namely constant impedance loads and induction motor loads. These two load types have different static and dynamic behaviour, which may influence both steady state and dynamic perfomance of the power network. Therefore, the optimal scheduling is performed to maintain or improve static voltage stability indicator (network loadability) and prevent undesirable dynamic response of demand in case of a disturbance. Finally, while the analysis presented in this paper was performed on a relatively small distribution network and using currently prevailing demand composition in distribution networks, the implications of DSM on a larger distribution or transmission network and different demand compositions (e.g., including larger shares of EVs and heat pumps) and flexibility would be even more significant. Therefore, any wide-scale DSM action should be taken only after analysing possible effects that the change in load magnitude and load composition at different load buses could cause in the network.

\section{REFERENCES}

[1] D. S. Callaway and I. A. Hiskens, "Achieving controllability of electric loads," Proceedings of the IEEE, vol. 99, pp. 184-199, 2011. "Demand Side Flexibility Annual Report 2016 - Power Responsive," National Grid, 2016, [Online].Available: http://powerresponsive.com/wp-content/uploads/2017/01/PowerResponsive-Annual-Report-2016-FINAL.pdf.

[3] M. Shaad, R. Errouissi, C. P. Diduch, M. E. Kaye, and L. Chang, "Aggregate Load Forecast with Payback Model of the Electric Water Heaters for a Direct Load Control Program," in 2014 IEEE Electrical Power and Energy Conference, 2014, pp. 214-219.

[4] O. Ma, K. Cheung, D. J. Olsen, N. Matson, M. D. Sohn, C. M. Rose, J. H. Dudley, S. Goli, S. Kiliccote, and P. Cappers, "Demand response and energy storage integration study," National Renewable Energy Lab.(NREL), Golden, CO (United States)2016.

[5] S. Kiliccote, D. Olsen, M. D. Sohn, and M. A. Piette, "Characterization of demand response in the commercial, industrial, and residential sectors in the United States," Wiley Interdisciplinary Reviews: Energy and Environment, vol. 5, pp. 288-304, 2016.

[6] P. P. Varaiya, F. F. Wu, and J. W. Bialek, "Smart operation of smart grid: Risk-limiting dispatch," Proceedings of the IEEE, vol. 99, pp. 40-57, 2011.

[7] A. Agnetis, G. Dellino, G. De Pascale, G. Innocenti, M. Pranzo, and A. Vicino, "Optimization models for consumer flexibility aggregation in smart grids: The ADDRESS approach," in 2011 IEEE First International Workshop on Smart Grid Modeling and Simulation (SGMS), Brussels, Belgium, 2011, pp. 96-101.

[8] K. Christakou, "A unified control strategy for active distribution networks via demand response and distributed energy storage systems," Sustainable Energy, Grids and Networks, vol. 6, pp. 1-6, 2016.

[9] A. Brooks, E. Lu, D. Reicher, C. Spirakis, and B. Weihl, "Demand Dispatch," IEEE Power and Energy Magazine, vol. 8, pp. 20-29, 2010.

[10] B. P. Hayes, "Distributed generation and demand side management: Applications to transmission system operation," $\mathrm{PhD}$ Thesis. University of Edinburgh, 2013. 
[11] I. Cobelo, "Active Control of Distribution Networks," PhD Thesis, The University of Manchester, 2005.

[12] B. J. Claessens, P. Vrancx, and F. Ruelens, "Convolutional Neural Networks for Automatic State-Time Feature Extraction in Reinforcement Learning Applied to Residential Load Control," IEEE Transactions on Smart Grid, vol. 9, pp. 3259-3269, 2018.

[13] D. J. Olsen, "Grid integration of aggregated demand response, part 1: load availability profiles and constraints for the western interconnection," Lawrence Berkeley National Laboratory, 2013, [Online].Available:

https://cloudfront.escholarship.org/dist/prd/content/qt6ps4r3xp/qt6ps 4r3xp.pdf.

[14] A. Jalali and M. Aldeen, "Modified modal analysis approach for distribution power systems," in 2017 IEEE PES Innovative Smart Grid Technologies Conference Europe (ISGT-Europe), Torino, Italy, 2017, pp. 1-6.

[15] Y. Zhu, "Ranking of Power System Loads Based on Their Influence on Power System Stability," First Year Transfer Report, The University of Manchester, 2016.

[16] "Preparing UK Electricity Networks for Electric Vehicles," [Online].Available: https://es.catapult.org.uk/wpcontent/uploads/2018/07/Preparing-UK-Electricity-Networks-for-

Electric-Vehicles-FINAL.pdf, 2018.

[17] Y. V. Makarov, D. J. Hill, and J. V. Milanovic, "Effect of load uncertainty on small disturbance stability margins in open-access power systems," in System Sciences, 1997, Proceedings of the Thirtieth Hawaii International Conference on, 1997, pp. 648-657.

[18] Y. Xu and J. V. Milanović, "Day-Ahead Prediction and Shaping of Dynamic Response of Demand at Bulk Supply Points," IEEE Transactions on Power Systems, vol. 31, pp. 3100-3108, 2016.

[19] M. Yao, J. L. Mathieu, and D. K. Molzahn, "Using demand response to improve power system voltage stability margins," in PowerTech, 2017 IEEE Manchester, 2017, pp. 1-6.

[20] J. Aghaei, M. I. Alizadeh, A. Abdollahi, and M. Barani, "Allocation of demand response resources: toward an effective contribution to power system voltage stability," IET Generation, Transmission \& Distribution, vol. 10, pp. 4169-4177, 2016.

[21] Y. Dong, X. Xie, W. Shi, B. Zhou, and Q. Jiang, "Demand-ResponseBased Distributed Preventive Control to Improve Short-Term Voltage Stability," IEEE Transactions on Smart Grid, vol. 9, pp. 4785-4795, 2018.

[22] M. Hummon, D. Palchak, P. Denholm, J. Jorgenson, D. J. Olsen, S. Kiliccote, N. Matson, M. Sohn, C. Rose, and J. Dudley, Grid Integration of Aggregated Demand Response: Part 2, Modeling Demand Response in a Production Cost Model: National Renewable Energy Laboratory, 2013.

[23] D. S. Kirschen, A. Rosso, M. Juan, and L. F. Ochoa, "Flexibility from the demand side," in Power and Energy Society General Meeting, 2012 IEEE, San Diego, CA, USA, 2012, pp. 1-6.

[24] J. Ponocko and J. V. Milanovic, "Forecasting Demand Flexibility of Aggregated Residential Load Using Smart Meter Data," IEEE Transactions on Power Systems, vol. PP, pp. 1-1, 2018.

[25] Y. G. Rebours, D. S. Kirschen, M. Trotignon, and S. Rossignol, "A Survey of Frequency and Voltage Control Ancillary Services\&mdash;Part I: Technical Features," IEEE Transactions on Power Systems, vol. 22, pp. 350-357, 2007

[26] D. Wang, S. Parkinson, W. Miao, H. Jia, C. Crawford, and N. Djilali, "Online voltage security assessment considering comfort-constrained demand response control of distributed heat pump systems," Applied Energy, vol. 96, pp. 104-114, 2012.

[27] Z. Bo and C. Yi-Jia, "Multiple objective particle swarm optimization technique for economic load dispatch," Journal of Zhejiang University-Science A, vol. 6, pp. 420-427, 2005.

[28] T. Niknam, M. Narimani, J. Aghaei, and R. Azizipanah-Abarghooee, "Improved particle swarm optimisation for multi-objective optimal power flow considering the cost, loss, emission and voltage stability index," IET Generation, Transmission \& Distribution, vol. 6, pp. 515-527, 2012.

[29] R. Hassan, B. Cohanim, O. De Weck, and G. Venter, "A comparison of particle swarm optimization and the genetic algorithm," in 46th AIAA/ASME/ASCE/AHS/ASC structures, structural dynamics and materials conference, Austin, TX, USA, 2005, p. 1897.

[30] R. Al Abri, E. F. El-Saadany, and Y. M. Atwa, "Optimal placement and sizing method to improve the voltage stability margin in a distribution system using distributed generation," IEEE Transactions on Power Systems, vol. 28, pp. 326-334, 2013.

[31] H. Hedayati, S. A. Nabaviniaki, and A. Akbarimajd, "A Method for Placement of DG Units in Distribution Networks," IEEE Transactions on Power Delivery, vol. 23, pp. 1620-1628, 2008.

[32] M. Ettehadi, H. Ghasemi, and S. Vaez-Zadeh, "Voltage StabilityBased DG Placement in Distribution Networks," IEEE Transactions on Power Delivery, vol. 28, pp. 171-178, 2013.

[33] "Microgrid Stability Definitions, Analysis, and Modeling," IEEEPES Task Force on Microgrid Stability Analysis and Modeling,2018.

[34] X. Tang and J. V. Milanović, "Assessment of the impact of demand side management on power system small signal stability," in 2017 IEEE Manchester PowerTech, 2017, pp. 1-6.

[35] Pecan Street Inc. Dataport 2017 [Online]. Available: http://www.pecanstreet.org/

[36] "Modelling and Aggregation of Loads in Flexible Power Networks," CIGRE WG C4.605 (566), ISBN: 978-2-85873-261-6, February 2014.

[37] H. Kun-Yuan and H. Yann-Chang, "Integrating direct load control with interruptible load management to provide instantaneous reserves for ancillary services," IEEE Transactions on Power Systems, vol. 19, pp. 1626-1634, 2004.

[38] W. Deh-Chang and C. Nanming, "Air conditioner direct load control by multi-pass dynamic programming," IEEE Transactions on Power Systems, vol. 10, pp. 307-313, 1995.

[39] K. M. Kosa, S. C. Cates, S. L. Godwin, R. J. Coppings, and L. Speller-Henderson, "Most Americans are not prepared to ensure food safety during power outages and other emergencies," Food Protection Trends, vol. 31, pp. 428-436, 2011.

[40] Y. Mansour, "Voltage stability of power systems: concepts, analytical tools, and industry experience," IEEE special publication, 1990.

[41] E. Ghahremani and I. Kamwa, "Optimal placement of multiple-type FACTS devices to maximize power system loadability using a generic graphical user interface," IEEE Transactions on Power Systems, vol. 28, pp. 764-778, 2013.

[42] R. C. Eberhart and Y. Shi, "Comparison between genetic algorithms and particle swarm optimization," in International conference on evolutionary programming, San Diego, CA, USA, 1998, pp. 611-616.

[43] D. W. Boeringer and D. H. Werner, "Particle swarm optimization versus genetic algorithms for phased array synthesis," IEEE Transactions on antennas and propagation, vol. 52, pp. 771-779, 2004.

[44] M. Clerc, Particle swarm optimization vol. 93: John Wiley \& Sons, 2010.

[45] J. V. Paatero and P. D. Lund, "A model for generating household electricity load profiles," International journal of energy research, vol. 30, pp. 273-290, 2006.

[46] "Electricity Distribution Systems Losses Non-technical Overview," Ofgem, 2009, [Online].Available: https://www.ofgem.gov.uk/publications-and-updates/electricitydistribution-systems-losses-non-technical-overview.

[47] J. Jardini, C. Tahan, S. Ahn, and E. Ferrari, "Distribution transformer loading evaluation based on load profiles measurements," IEEE Transactions on Power Delivery, vol. 12, pp. 1766-1770, 1997.

Jelena Ponoćko (S'15, M'19) received her PhD degree at The University of Manchester, UK, where she is currently working as a research associate in the areas of demand response and load profiling.

Jovica V. Milanović (M'95, SM'98, F'10) is a Professor of Electrical Power Engineering, Deputy Head of School and Director of External Affairs in the School of Electrical and Electronic Engineering at The University of Manchester, U.K. 